\title{
Theoretical and Experimental Evaluation of a Compact Aerosol Wind Tunnel and its Application for Performance Investigation of Particulate Matter Instruments
}

\author{
Prashant Patel ${ }^{1,2}$, Shankar G. Aggarwal ${ }^{1,2^{*}}$ \\ ${ }^{1}$ Gas Metrology, Environmental Sciences \& Biomedical Metrology Division, CSIR-National \\ Physical Laboratory, Dr. K.S. Krishnan Marg, New Delhi, 110012, India \\ ${ }^{2}$ Academy of Scientific and Innovative Research (AcSIR), Ghaziabad, 201002, India
}

\section{ABSTRACT}

In this study, we developed a compact low-speed wind tunnel. First, we computationally analysed the flow quality of different wall shapes for the contraction section, the most critical part of a wind tunnel, and selected the design exhibiting minimal boundary layer separation at simulated flow velocities of 2 and $8 \mathrm{~km} \mathrm{~h}^{-1}$. Then, after constructing the wind tunnel, we experimentally evaluated its overall performance based on different parameters per the United States Environmental Protection Agency (U.S. EPA) guidelines (40 CFR 53.62). The air velocity and turbulence profiles were uniform, displaying $\leq 10 \%$ variation in the section we tested. Additionally, we measured the mass concentrations and size distributions of polydisperse dust particles, which were generated by a custom-made rotary dust feeder to ensure the homogeneity of the aerosol, inside the wind tunnel at air velocities of 2 and $8 \mathrm{~km} \mathrm{~h}^{-1}$ and found $\leq 10 \%$ deviation for the mean values across the test section relative to those for the central sampling point. We also assessed the effectiveness of the Well Impactor Ninety-Six (WINS) and Very Sharp Cut Cyclone (VSCC) in the wind tunnel at an air velocity of $8 \mathrm{~km} \mathrm{~h}^{-1}$ by determining the $D_{50}$ cutoffs, which, being $2.44 \pm 0.05$ $\mu \mathrm{m}$ and $2.54 \pm 0.05 \mu \mathrm{m}$, respectively, fulfilled U.S. EPA's criteria. Furthermore, we compared the performance of a low-cost sensor against that of a reference instrument in measuring $\mathrm{PM}_{2.5}$ concentrations, and our results agreed with those from previous studies.

Keywords: Wind tunnel, Theoretical designing, CFD evaluation, D50 cutoff of WINS and VSCC, Performance check of PM sensor

Revised: March 20, 2021

Accepted: March 25, 2021

${ }^{*}$ Corresponding Author:

aggarwalsg@nplindia.org

\section{Publisher:}

Taiwan Association for Aerosol Research

ISSN: $1680-8584$ print

ISSN: 2071-1409 online

cc) Copyright: The Author(s). This is an open access article distributed under the terms of the Creative Commons Attribution License (CC BY 4.0), which permits unrestricted use, distribution, and reproduction in any medium, provided the original author and source are cited.

\section{INTRODUCTION}

Rapid urbanisation, industrialisation and steep population growth have led to the significant degradation of air quality in countries like China and India. Most of the time air quality, especially of megacities shows poor index (Greenstone and Hanna, 2014). In fact, in one of the major findings, it is estimated that more than half of India's population is exposed to ambient $\mathrm{PM}_{2.5}$ concentration that do not comply with India's National Ambient Air Quality Standards (NAAQS) (Purohit et al., 2019). In November 2019, the air quality index (AQI) of Delhi hit 500 indices for the first time which denotes poorest air quality of all time (Mansoor, 2019).

Ambient particles are important pollutants and therefore to assure air quality compliances, $\mathrm{PM}_{2.5}$ is used to monitored continuously in most of the air quality monitoring stations. As per NAAQS, present days in India, $\mathrm{PM}_{2.5}$ is measured by gravimetric and beta gauge mass measuring methods, where $\mathrm{PM}_{10}$ inlet and $\mathrm{PM}_{2.5}$ cyclone or impactor are used as a separation device (NAAQS, 2009). Sampler effectiveness is overall dependent on sampler inlet and separation devices. Evaluation of PM samples is important before they deploy for field sampling (Aggarwal et al., 2013). 
Also, PM measurement affects the intended purpose of the sampling, like chemical composition of $\mathrm{PM}_{2.5}$ (Kumar et al., 2020). Varying meteorology and composition of ambient environment makes it difficult to evaluate these samplers on field itself.

Therefore, aerosol wind tunnels are typically used for the evaluation of sampler effectiveness studies, e.g., $D_{50}$ cutoff of PM sampler, where aerosol of different sizes is dispersed in controlled manner to sampler under test at different unidirectional wind speeds (Wagner and Leith, 2001). Table 1 summarises different types of aerosol wind tunnels with their characteristics and for the purposes they have been used in literature. The aerosol wind tunnel is not limited to use only to PM sampler effectiveness testing but also used for studying filter and cloth penetration efficiency (Jaques et al., 2011), respiration study (Hinds and Kuo, 1995), etc. (Table 1).

Wind tunnels can be classified majorly into two or different types such as open or closed type and compact or large wind tunnels. The design of a wind tunnel with the sole objective of keeping uniform distribution of particles in the test section is critical for evaluation of PM samplers. Each type of wind tunnel has its own advantages and disadvantages, which are described in detail in Cattafesta et al. (2010). The basic design configuration consists of several parts which include settling chamber, contraction section, stability section, test section, exit diffuser and fan section with the purpose of maintaining constant air uniformity and low turbulence in test section using honeycomb flow straightener and screens (Cattafesta et al., 2010) in settling chamber. The design of each part is critical to the performance of a wind tunnel.

Furthermore, the designing of the contraction section is one of the most critical tasks as contraction increases the flow velocity of air and hence controls the air turbulence in wind tunnel. Thus, poor design of contraction often contributes to turbulence in a wind tunnel. Design based on high contraction ratio (CR; inlet/outlet area), and without any curvier designing to smoothly reduction in cross-section area of inlet to outlet often leads to boundary layer separation at the inlet which may create turbulence or eddy near the wall of wind tunnel (Mehta and Bradshaw, 1979). Moreover, because of this instability, the dust mixing and dispersion inside the tunnel may vary from position to position at the test section. As mentioned in Table 1, in most of the studies of low-speed aerosol wind tunnels, the performance of the tunnel was tested according to U.S. EPA-specified requirements without giving much of the necessary information on the development of these wind tunnels, especially the contraction section of the tunnel.

Moreover, Table 1 also shows various methods for aerosol generation, dosing and distribution systems. Basically, it can be classified into two types, (1) moving and (2) static type. Ranade et al. (1990) used counter-rotating mixing fan and Cheng et al. (2004) adapted air blender which are the example of static-type particle dosing and distribution systems. On the other hand, Lee et al. (2013) used vertically moving aerosol distribution system to maintain aerosol uniformity inside the test section. Moreover, it is important to note that moving-type aerosol distribution system may cause irregularity in wind speed stability at the test section (Hinds and Kuo, 1995). Apart from contraction and aerosol distribution system designing, settling chamber configuration is equally important task. It is a place where high-efficiency particulate air (HEPA) filters and flow straighteners (honeycomb and screens) are placed. More importantly, its dimension is dependent on contraction inlet (Mehta and Bradshaw, 1979).

Therefore, in this work, we reconsider the problems associated with the design of low-speed aerosol wind tunnel and developed a compact low-speed aerosol wind tunnel, where design of contraction is studied by comparing the contraction design model equation side by side. Accordingly, a wind tunnel is developed and uniformity of desired wind speed and aerosol homogeneity inside test section is validated experimentally. Finally, the objective was to meet the requirements of wind tunnel as specified in U.S. EPA (2006) guidelines (40 CFR 53.42: Generation of test atmospheres for wind tunnel tests) for the calibration of PM samplers which are as follow:

1) The wind speed measured at any test point in the test section shall not differ by more than $10 \%$ from the mean wind speed in the test section.

2) An array of not less than 5 evenly spaced isokinetic samplers shall be used to determine the particle concentration uniformity in the sampling zone. If the particle concentration measured by any single isokinetic sampler in the sampling zone differs by more than $10 \%$ from the mean concentration, the particle delivery system is unacceptable in terms of uniformity of particle concentration.

Our theoretical and experimental evaluation suggested that design of the developed wind 


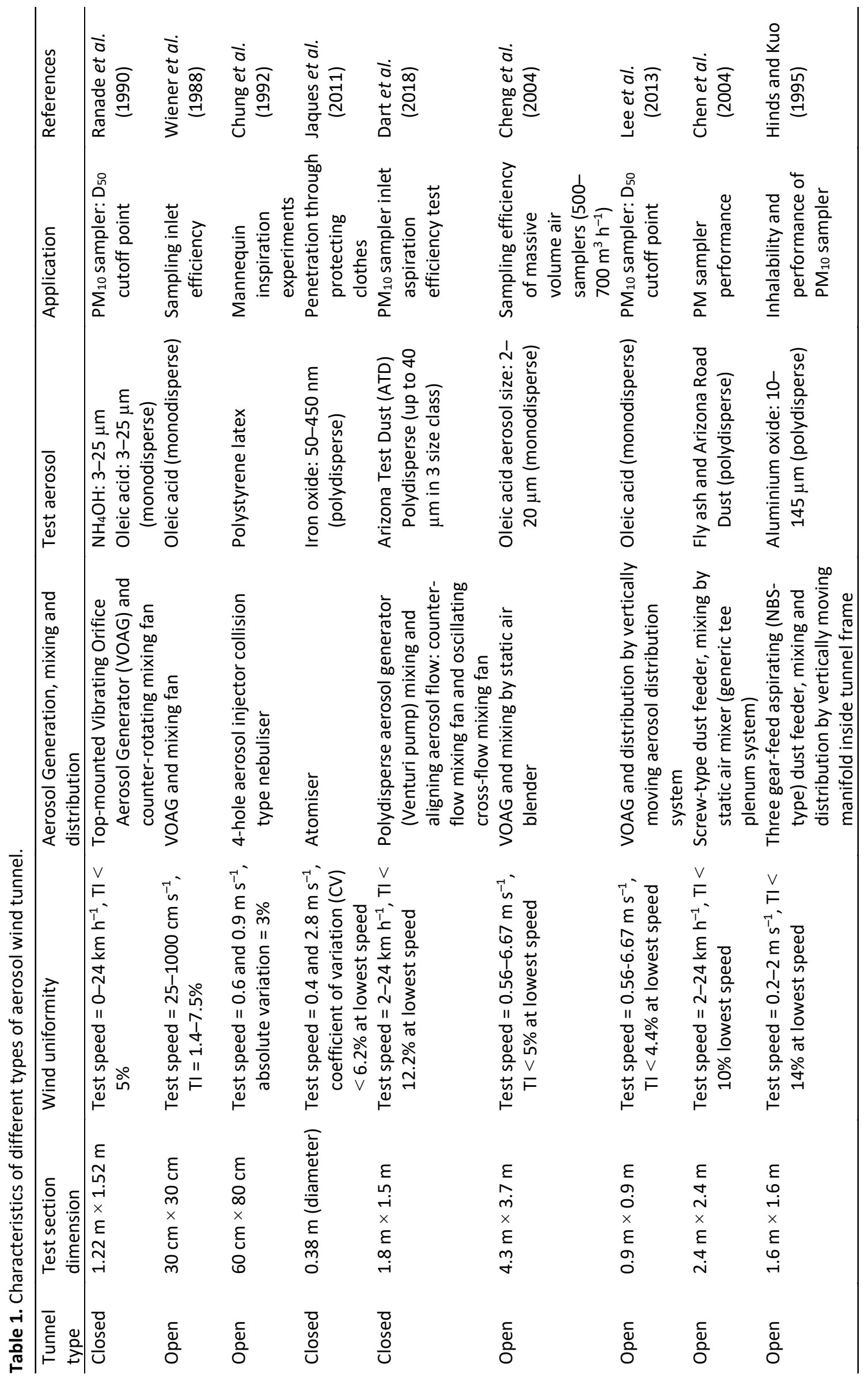


tunnel is well agreed to the above criteria. We also discussed the results of $D_{50}$ cutoff determination of a PM2.5 WINS impactor and VSCC cyclone and performance check of a PM sensor using this wind tunnel, which are in agreement with the reference studies.

\section{MATERIAL AND METHODS}

\subsection{Wind Tunnel Design and Description}

The developed wind tunnel is of open type. It consists of settling chamber, contraction section, flow-stabilising duct, test section, exit diffuser and blower (fan) section. The test section dimension is $0.34 \mathrm{~m} \times 0.34 \mathrm{~m}$ and with overall length of the tunnel is $4.2 \mathrm{~m}$. In this work, a square-shaped test section and other sections were preferred to design to achieve the best possible flow quality similar to that in a circular-shaped test section. In addition, the current square-shaped test section overcomes the impracticability of circular-shaped test section, e.g., in our case, it is needed to place additional aerosol instruments, and thus the alignment and arrangement for holding the instruments are convenient in square-shaped test section without the use of supportive system, i.e., without any obstacles which can create pressure gradients and thus affect the flow quality.

The tunnel is compact, easy to operate and performance is similar to a conventional wind tunnel but at the same time requires less capital to operate on a day-to-day basis. The test section dimension is not enough to test the large PM inlets and the aerosol-measuring instruments, but it has certain advantages over large-sized wind tunnel (test section), e.g., (1) easy to maintain and stabilise the flow quality, (2) requires less test particles or certified reference materials (CRMs) to maintain the same concentration as in the large wind tunnels, (3) enough particle number and mass of bigger-sized particle can be achieved and maintained in the test section as elutriation is reduced, and also (4) the construction is cost-effective and need a less space for installation. The layout of the tunnel along with different external equipment used is shown in Fig. 1(a), whereas a photograph of developed aerosol wind tunnel is shown in Fig. 1(b).

The settling chamber draws room air inside the tunnel (room size is $\mathrm{L}=14 \mathrm{~m}, \mathrm{~W}=4 \mathrm{~m}, \mathrm{H}=2.7 \mathrm{~m}$ ). It consists of a pre-filter and HEPA filter which filter the incoming air. Performance of filters were measured by pressure drop across the filter and accordingly cleaned/changed. The flow Reynolds number at wind speed of $8 \mathrm{~km} \mathrm{~h}^{-1}$ inside the test section is $\sim 4.9 \times 10^{4}$. The settling chamber also consists of honeycomb flow straightener which helps in breaking up the larger scales of unsteadiness of incoming air. The selected honeycomb has a porosity of 0.9 , which is slightly greater than the recommended porosity of 0.8 (Mehta and Bradshaw, 1979).

The contraction is the second part of wind tunnel which is in continuation to the settling chamber. The contraction increases the mean flow velocity and it aligns the flow into the test section. The design of contraction is critical to overall wind tunnel flow performance.

In present design, we first simulated the design of contraction wall shape for low-speed tunnel. Design Eq. (1), given by Bell and Mehta (1988), is a fifth-degree polynomial equation, and has been the most widely used equation for designing of low-speed wind tunnels, while Eq. (2) was given by Fang et al. (2001), and was derived especially for contraction of square-to-square shape and obtained from Morel (1975) design procedure. The design equation consists of two subequations, i.e., combination of two matched cubics, which were divided at $X_{m}\left(x_{m} / L\right)$ point called matched point. Both design equations were used to design a contraction wall shape as shown in Fig. 2 after fixing the inlet and outlet dimensions.

In Fig. 2, the hydraulic dimensions of inlet $\left(2 H_{i}\right)$ and outlet $\left(2 H_{0}\right)$ are $68 \mathrm{~cm}$ and $34 \mathrm{~cm}$, respectively. The total length of contraction $(L)$ is of $68 \mathrm{~cm}(0 \mathrm{~cm} \leq x \leq 68 \mathrm{~cm})$. The inlet of contraction is continuous to settling chamber $(68 \mathrm{~cm} \leq x \leq 148 \mathrm{~cm})$. From the outlet $(-20 \mathrm{~cm} \leq x$ $\leq 0 \mathrm{~cm}$ ) is extended to investigate flow quality after the increase in wind speed. A contraction area ratio of 5 is used to design the contraction. The given dimensions along with honeycomb of length $10 \mathrm{~cm}$ inside the settling chamber is used as computational domain to simulate the flow. Based on simulated flow performance, we developed the contraction design and performed the experimental characterisation of air flow and dust uniformity. To maintain the simplicity, the results of flow simulation given by Bell and Mehta (1988) and Fang et al. (2001) were called as $D 1$ and $D 2$, respectively and explained accordingly. 

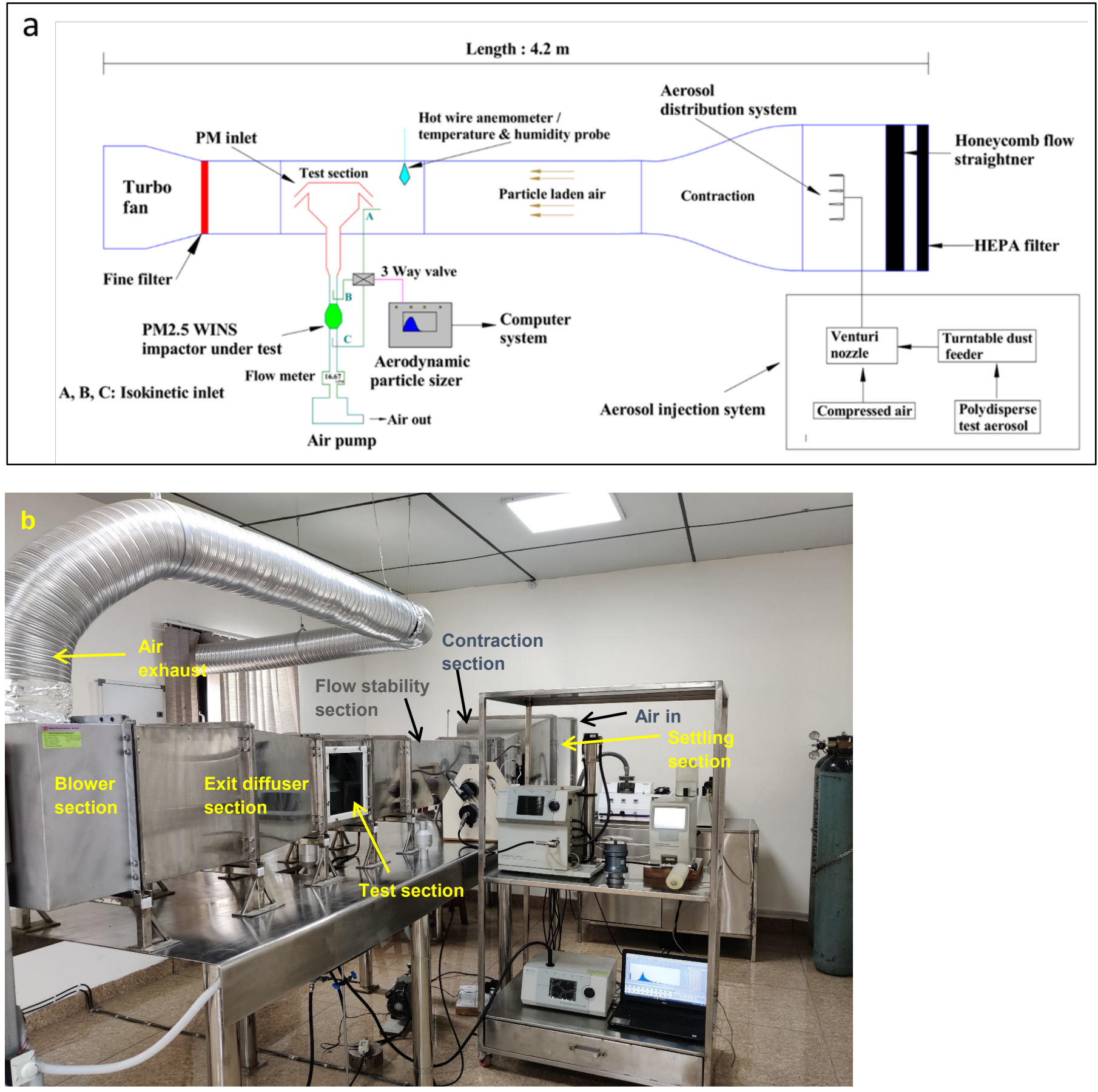

Fig. 1. (a) Schematic of aerosol wind tunnel with all arrangements. (b) A photograph of developed aerosol wind tunnel.

Design Eq. (1):

$$
Y=H_{i}-\left(H_{i}-H_{o}\right)\left[6\left(\frac{x}{L}\right)^{5}-15\left(\frac{x}{L}\right)^{4}+10\left(\frac{x}{L}\right)^{3}\right]
$$

Design Eq. (2):

$$
Y=\left(H_{i}-H_{o}\right)\left[1-\frac{1}{X_{m}^{2}}\left(\frac{x}{L}\right)^{3}\right]+H_{o}, \quad x<x_{m}
$$


$Y=\frac{\left(H_{i}-H_{o}\right)}{\left(1-X_{m}\right)^{2}}\left[\left(1-\frac{x}{L}\right)^{3}\right]+H_{o}, \quad x>x_{m}$

The detailed equations and important parameters of contraction are given in Table 2 (also see Fig. 2). From contraction, air enters to flow-stabilising duct where flow is stabilised; after that air further travels to test section. Downstream to test section, air passes through exit diffuser which has gentle expansion $\left(<5^{\circ}\right)$ to decelerate the speed of flow from test section, thereby achieving static pressure recovery and reducing the load on blower. The drive system or fan section follows the exit diffuser at the end which consists of direct drive backward curved fan.

A turntable-type dust feeder is used to dispense the dry polydisperse dust inside the tunnel using Venturi nozzle. The Venturi pump outlet consists of 4-conical nozzle system inside the settling chamber of wind tunnel for dosing and distribution of test aerosols (Fig. 1(a)).

\subsection{Numerical Simulation of Contraction Design}

The basic steps for computational fluid dynamics (CFD) simulation were followed which

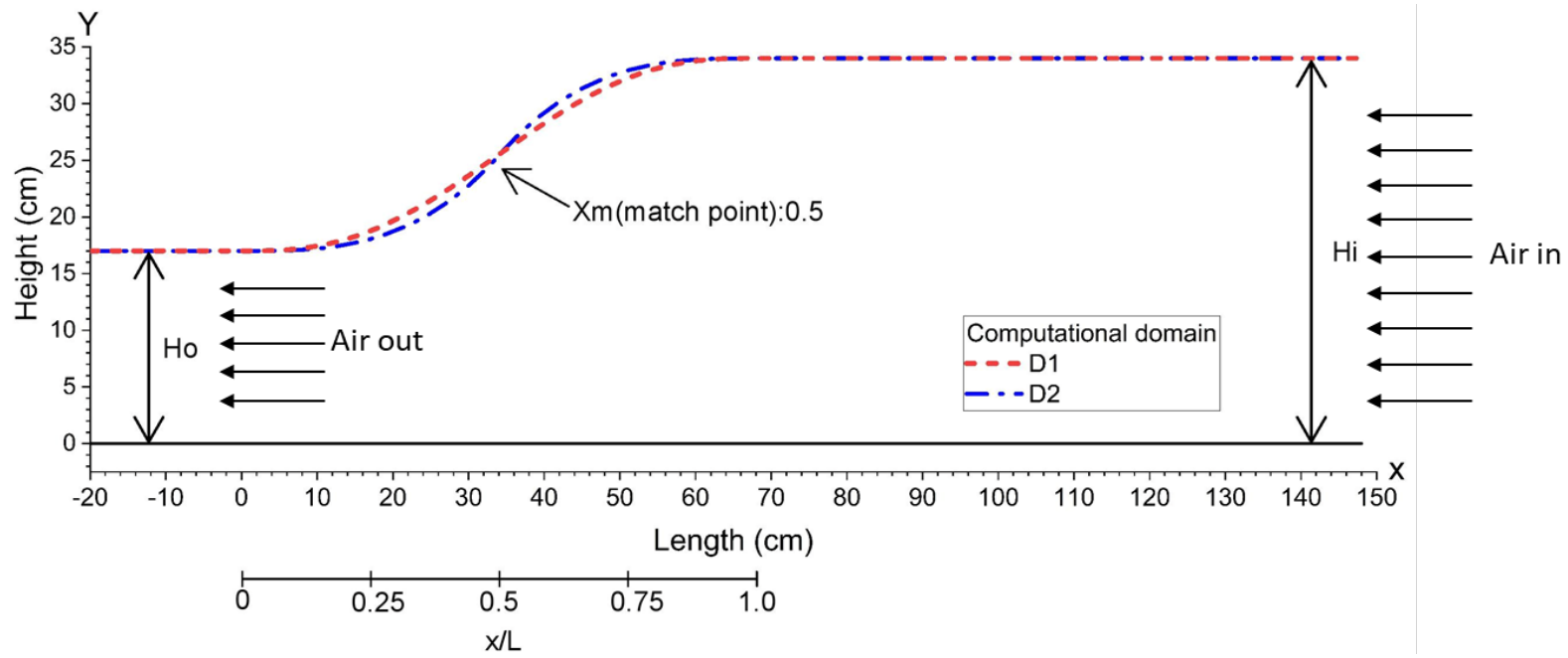

Fig. 2. Schematic of computational domain and contraction designs D1 and D2.

Table 2. Contraction important design parameters.

\begin{tabular}{ll|l}
\hline Contraction length $(\mathrm{L})$ & $68 \mathrm{~cm}$ & $\begin{array}{l}\text { Contraction wall shape design } \\
\text { D1 Equation }\end{array}$ \\
Height of inlet $\left(\mathrm{H}_{\mathrm{i}}\right.$ ) (half symmetry plane) & $34 \mathrm{~cm}$ & $Y=34-(34-17)\left[6\left(\frac{x}{68}\right)^{5}-15\left(\frac{x}{68}\right)^{4}+10\left(\frac{x}{68}\right)^{3}\right]$ \\
Height of outlet $\left(\mathrm{H}_{\mathrm{o}}\right)$ (half symmetry plane) $17 \mathrm{~cm}$ & D2 Equation \\
Contraction area ratio & 5 & $Y=(34-17)\left[1-\frac{1}{X_{m}^{2}}\left(\frac{x}{68}\right)^{3}\right]+17, \quad x<x_{m}$ \\
& $Y=\frac{(34-17)}{\left(1-X_{m}\right)^{2}}\left[\left(1-\frac{x}{68}\right)^{3}\right]+17, \quad x>x_{m}$ \\
\end{tabular}




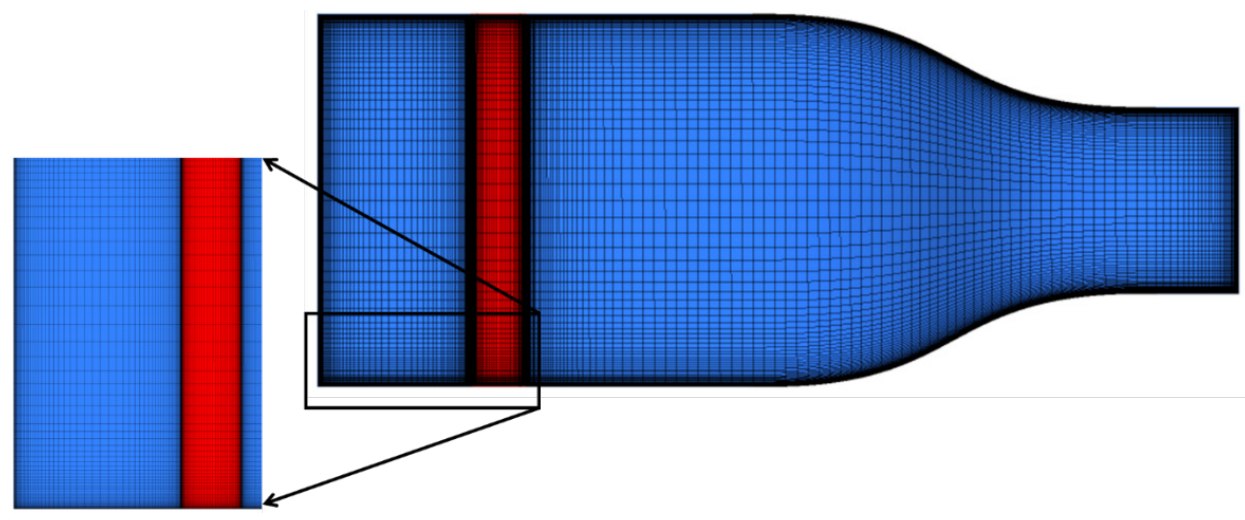

Fig. 3. Schematic of structured hexahedral mesh. Red-coloured part is porous zone present in settling chamber.

includes (1) the geometry generation, (2) meshing of fluid domain, (3) numerical solution, and (4) post-processing of fluid flow. The CFD simulation is carried out by Ansys Fluent Solver Release 18 (Ansys, 2017). A 3-D geometry is designed and computational mesh is generated in fluid domain with quadrilateral element which is denser at near the wall to capture the boundary layer effect as shown in Fig. 3. The distance to the first node point above the wall is set such that nondimensional $y+$ is less than 1. The computational domain is already explained in Section 2.1 and Fig. 2. The flow is assumed to be steady, three-dimensional, incompressible and turbulent. A turbulence is modelled by Shear Stress Transport (SST) k- $\omega$ model with double-precision option. The model is capable of predicting the flow near the wall more accurately as it is combination of standard $k-\varepsilon$ model in the free stream and Wilcox $k-\omega$ model in wall regions. The working fluid is air and assumed as an ideal gas. The SIMPLE algorithm is used for pressure velocity coupling and second-order upwind scheme is applied for the equation of momentum, turbulent kinetic energy and dissipation rate. At the inlet of settling chamber, instead of designing honeycomb flow straightener as a whole, we used porous zone model to observe the effect of honeycomb structure, since it is difficult to mesh the finer details and size of honeycomb structure. Moreover, meshing and simulating the honeycomb structure require more computational power and time. In porous zone model, the values of inertial and viscous resistance are critical (Ansys, 2017). The values of resistance are calculated empirically by plotting the experimentally determined curve between different air velocities and corresponding pressure changes for honeycomb flow straightener. The inertial loss factor, $\mathrm{C}_{2}\left(\mathrm{~m}^{-1}\right)$, is calculated according to the equations given in Fluent documentation (Ansys, 2017).

Model validation and mesh independency study was also performed. In this, experimental and numerical results of contraction design studied by Zanoun (2018) and Kao et al. (2017) using Design Eqs. (1) and (2), respectively were replicated in CFD model. Each model shows the basic features, which are prevalent in contraction fluid flow such as at central region of contraction has maximum velocity. Inside and near to the wall region, a low region velocity is observed due to frictional shear stress with wall.

The D2 model was chosen and simulated at outlet velocity of $\sim 0.56 \mathrm{~m} \mathrm{~s}^{-1}$ to identify the suitable mesh density to capture the sensitive details near the centre, and wall of contraction. Four different mesh density were structured, and simulation were performed. The coarse, medium, fine and extra fine mesh has $2.2 \times 10^{4}, 6.3 \times 10^{4}, 3.6 \times 10^{5}$ and $1.1 \times 10^{6}$ number of cells, respectively. The parametric study results are shown in Fig. 4 in terms of axial velocity across the contraction, velocity distribution at contraction outlet $(x / L=0)$ horizontal and diagonal respectively. Fine and extra fine mesh have almost similar results as compare to coarse and medium mesh. The medium and fine mesh have small differences in axial and horizontal velocity distribution. The diagonal velocity shows sharp changes in velocity at corners of wall in medium and fine mesh setting as compare to that of coarse mesh. The contour Fig. 4(d) at different mesh setting of contraction outlet $(x / L=0)$ also shows same pattern near the wall and corners. Overall, fine mesh setting is consistent and predict the fluid flow behaviour well with very little differences in comparison to medium mesh is used in present study of contraction design. 


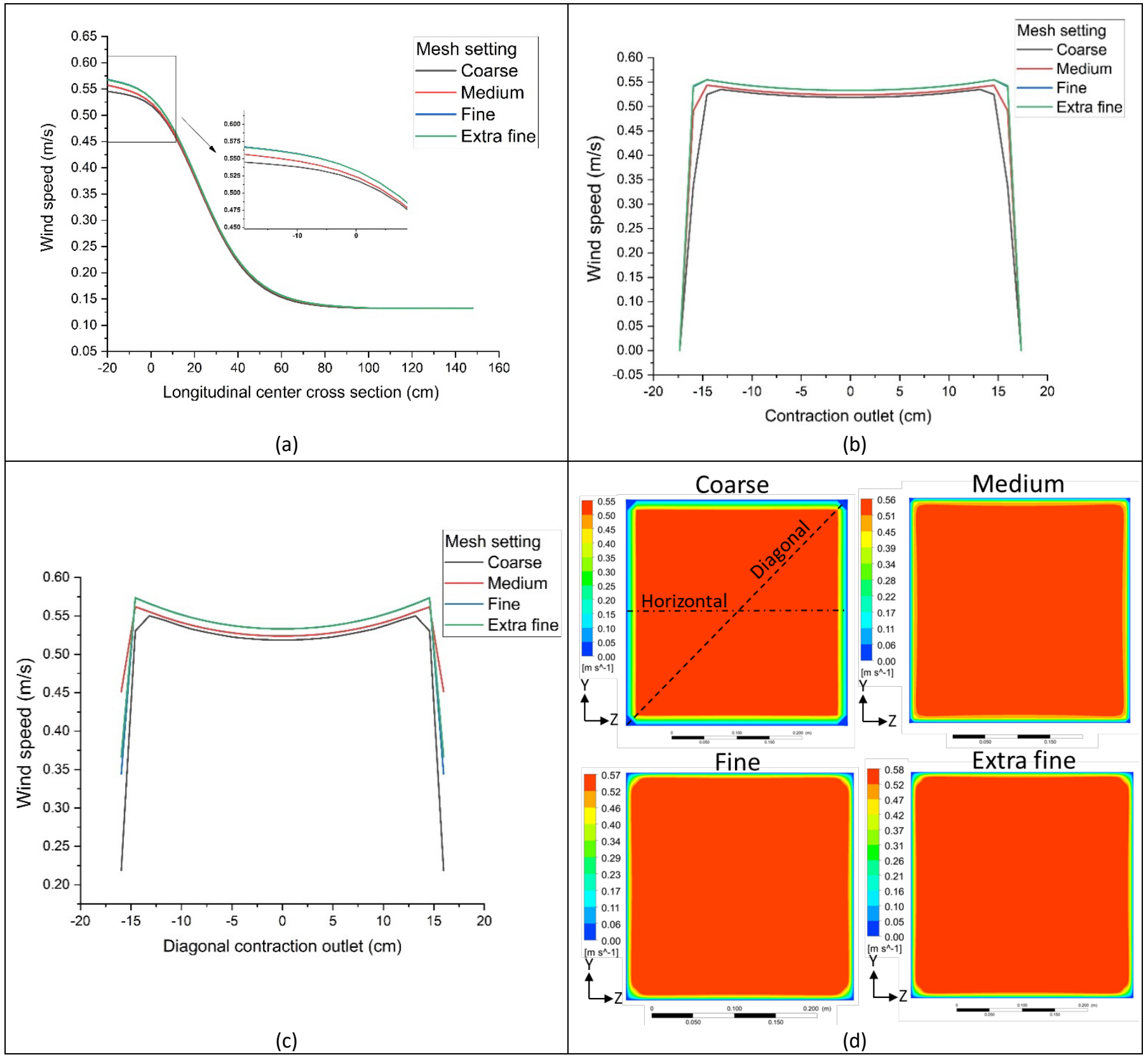

Fig. 4. Velocity profiles at different mesh density settings: (a) centreline, (b) horizontal at contraction outlet $(x / L=0)$, (c) diagonal (corner to corner) at contraction outlet $(x / L=0)$, (d) contour plot at contraction outlet $(x / L=0)$.

\subsection{Air Velocity Assessment Test}

Experimental determinations of air velocity uniformity and turbulence are carried out inside the test section. Air velocities are measured at wind speeds of $2 \mathrm{~km} \mathrm{~h}^{-1}$ and $8 \mathrm{~km} \mathrm{~h}^{-1}$ using a calibrated hotwire anemometer (Model 405i; Testo India Pvt. Ltd.). The data are recorded at 25 locations in a cross-sectional area of test section as shown in Fig. 5. At each location, the wind speed data is recorded at $2 \mathrm{~s}$ interval for $3 \mathrm{~min}$ in duplicate sets. Turbulence intensity is estimated by dividing the standard deviation of the measured wind speed by the mean wind speed at each location (Weiner et al., 1988; Lee et al., 2013).

\subsection{Aerosol Uniformity Test}

A customised turntable-type dust feeder, which is based on the design given in Reist and Taylor (2000) is used for dust dosing in the wind tunnel. It has a circular groove of multiple size ( $2 \mathrm{~mm}$ 


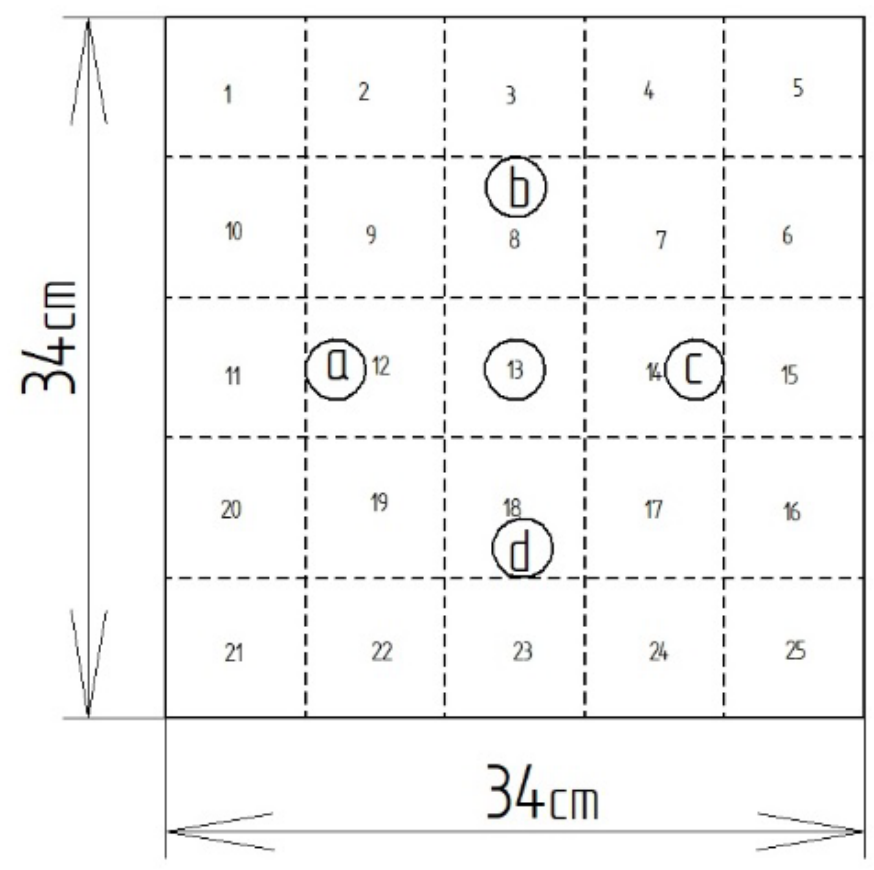

Fig. 5. Test section grids (1-25) for wind speed uniformity, and the circular marks are isokinetic sampler location for aerosol uniformity test.

and $3 \mathrm{~mm}$ in width) and $1.5 \mathrm{~mm}$ in depth. The rotation of turntable ( $2 \mathrm{rpm}$ ) was controlled using the stepper motor by ATmega-based microcontroller (Rev3; Genuino, Italy). In groove, the dust gets deposited and Venturi pump (Model JS90M; Vaccon Co., Inc., USA) used to dispense it inside the tunnel. The Venturi pump outlet is divided into 4-conical nozzle system, which is placed at the centre of the settling chamber. The dust used in this experiment was collected using a customised high-volume cyclone sampler (Okuda et al., 2015). The dust feeding rates inside the tunnel is $3-5 \mathrm{~g} \mathrm{~min}^{-1}$. The mean particle size of collected dust was $1.5 \mu \mathrm{m}$, and particle size distribution range was in between 0.5 to $6.5 \mu \mathrm{m}$.

To measure particle distribution, both gravimetric and real-time methods was used. Five isokinetic probes were placed inside the test section as shown in Fig. 5. A $47 \mathrm{~mm}$ filter (PTFE; Micro Separations, India) is used to collect the dust for a time duration varied in between 20$40 \mathrm{~min}$. This time duration is enough to collect measurable dust onto the filter to weigh on microbalance (MT5; Mettler Toledo, USA) of $0.001 \mathrm{mg}$ sensitivity which is coupled with an electrostatic charger (PRX U Set; Haug GmbH \& Co. KG, Germany). For real-time measurement of concentration distribution, an Aerodynamic Particle Sizer (APS) (Model 3321; TSI Inc., USA) was used. This APS can count particles in size ranges from $0.5-20 \mu \mathrm{m}$ in 54 size bins. The samples were collected using multiple isokinetic probes at the marked locations in test section as shown in Fig. 5. The probe was connected directly to APS one at time. The time interval for sampling at each marked location was $5 \mathrm{~min}$. The samples were taken in triplicate, and average particle count is calculated.

Since the dust feeder is custom-made, its particle dosing variability was calculated in terms of particle concentration stability in a probe inside the test section, i.e., the standard deviation of $N$ number of samples taken from an isokinetic probe to APS. In general, when this standard deviation within $N$ number of samples taken from a probe is calculated to be almost the same, the dust feeder dosing is believed to be stable.

\subsection{Impactor Penetration Efficiency and Low-cost Sensor Performance Testing}

\subsubsection{Testing of $\mathrm{PM}_{2.5}$ sampler}

Federal Reference Method for sampling of $\mathrm{PM}_{2.5}$ requires the use of $\mathrm{PM}_{2.5}$ WINS impactor as size segregator. Its design is prescribed by U.S. EPA (1998). In addition, PM2.5 VSCC cyclone (Mesa Laboratories, Inc., USA) is another size segregator which is verified by U.S. EPA and equivalent to 
WINS impactor also tested. PM2.5 WINS impactor was developed as per U.S. EPA (Kentek Inc., Korea). The experimental wind tunnel setup is depicted in Fig. 1(a). The test wind speed was $2.22 \mathrm{~m} \mathrm{~s}^{-1}\left(8 \mathrm{~km} \mathrm{~h}^{-1}\right)$. $\mathrm{PM}_{10}$ inlet was kept inside the test section for particle sampling and WINS impactor or VSCC cyclone was placed outside and was connected to pump. The isokinetic sampling probes $A, B$ and $C$ as shown in Fig. 1(a) were used to sample the test aerosol to APS. These probes were connected to APS one at time to determine the penetration efficiency (PE) (Eq. (8)). The fitting of plot between PE versus aerodynamic particle size is used to determine the $D_{50}$ cutoff size, and the results are explained and discussed in "Results" Section 3.4.1:

$P E=\left[\frac{N_{\text {after_WINS(D) }}}{N_{\text {before_WINS(D) }}}\right] \times 100$

where, $N_{\text {after_WINS(D) }}$ and $N_{\text {before_WINS(D) }}$ are the particle number concentration of size $D$ after and before impactor or cyclone (measured by Probe C and B in Fig. 1(a)), respectively.

\subsubsection{Testing of low-cost PM sensor}

Low-cost PM sensors are now becoming a choice of air quality community, and these sensors have been deploying for wide range of monitoring applications, e.g., in close network for better trace the emission sources and hotspots, biomass burning and forest fire emission measurements, in indoor environment, such as cooking emission measurement (Kelleher et al., 2018; Coffey et al., 2019; Li et al., 2020). There are several models of PM sensors available which can reasonably measure very high particle concentration, therefore appropriate to use at emission source also.

Therefore, for testing their performance, we need a particle generator which can generate very high particle concentration in wind tunnel application. Also as discussed above, because sensors are widely used for smoke emission measurements, we also used incense sticks (dhoop batti) to generate smoke test particles in our wind tunnel application for testing of performance of PM sensors. A custom Venturi smoke generator is used for smoke generation.

For this study, we used Plantower PM sensors (PMS3003). The maximum concentration which can be measured using this sensor as per specification is $1000 \mu \mathrm{g} \mathrm{m}^{-3}$. The response rate of PMS3003 is of $1 \mathrm{~s}$. The PMS3003 works on the principle of laser scattering; it has laser, a particle chamber and photodiode to detect the scattering of light by particle. The outlet of PMS3003 consists of small fan to draw air out from particle chamber. The PMS3003 data was handled using microcontroller (Rev3; Genuino, Italy) by a serial communication. The $\mathrm{PM}_{2.5}$ data was recorded at interval of $1 \mathrm{~min}$ average. The aerosol intake flow is low in PMS3003; therefore, all experiments related to PMS3003 were conducted at wind speed of $0.56 \mathrm{~m} \mathrm{~s}^{-1}\left(2 \mathrm{~km} \mathrm{~h}^{-1}\right)$.

In wind tunnel testing, first two PM sensors were placed at the centre of test section to check any manufacturing defect. Then single sensor was tested against the APS for particle concentration. Isokinetic probe was used to sample particle inside the test section of the tunnel. The isokinetic outlet and APS were connected using dilution chamber. The dilution chamber was used to dilute the particle number concentration because APS is sensitive to particle number concentration; the coincidence error caused by high particle concentration may decrease the measurement accuracy (Model 3321 Aerodynamic Particle Sizer Spectrometer Instruction Manual, 2012). The use of such particle dilution system minimizes the errors associated with APS measurement at high particle concentration. A dilution factor of 7 is determined experimentally. The sampling time interval for both APS and PM sensor is set to $1 \mathrm{~min}$. The performance of PM sensor inside the tunnel against the reference APS is discussed in "Results" Section 3.4.2.

\section{RESULT AND DISCUSSIONS}

\subsection{CFD Simulation}

To validate the theoretical equation-based design (D1 and D2) of contraction section of lowspeed wind tunnel, flow simulation was performed as mentioned in Section 2.2 using a CFD model. The D1 and D2 contraction model were validated for outlet wind speeds of $0.56 \mathrm{~m} \mathrm{~s}^{-1}$ and $2.22 \mathrm{~m} \mathrm{~s}^{-1}$, since given wind speeds are required as per U.S. EPA to determine the collection 


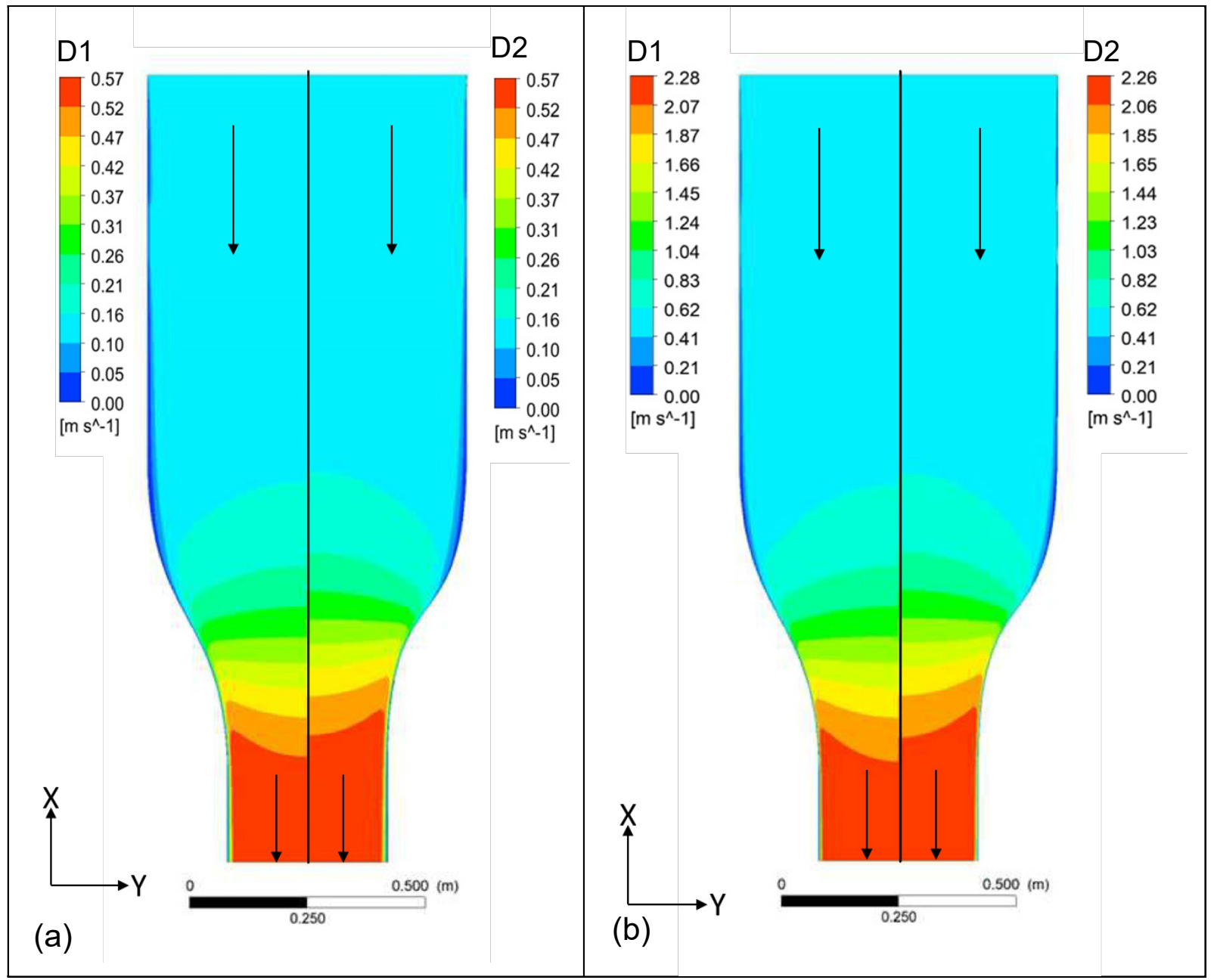

Fig. 6. The side-by-side view of velocity profiles at longitudinal centre plane for designs D1 and D2 at outlet wind speeds of (a) $0.56 \mathrm{~m} \mathrm{~s}^{-1}$ and (b) $2.22 \mathrm{~m} \mathrm{~s}^{-1}$, respectively.

efficiency of PM samplers. The contraction designs, D1 and D2 were validated in two ways. First the design difference based on contraction wall shape, and secondly its effect on flow quality at the outlet of contraction, i.e., cross-section shape.

Figs. 6(a) and 6(b) show the longitudinal cross-section of designs D1 and D2 at wind speeds of $0.56 \mathrm{~m} \mathrm{~s}^{-1}$ and $2.22 \mathrm{~m} \mathrm{~s}^{-1}$, respectively. The D1 and D2 at both wind speeds show the smooth increase in speed. Both designs take different approaches to reach at desired wind speed. The D2 starts early gain in speed as compared to D1, and also at outlet it starts attaining desired wind speed before D1 design.

Figs. 7(a) and 7(b) show the cross-section of outlet at position of $x=-20 \mathrm{~cm}$ for the designs D1 and D2 at wind speeds of $0.56 \mathrm{~m} \mathrm{~s}^{-1}$ and $2.22 \mathrm{~m} \mathrm{~s}^{-1}$, respectively. Both designs indicate the uniform wind speed in majority of area. However, at corner of the wall a "backward C"-shaped boundary is visible. This phenomenon is generally observed in square-shaped wind tunnel. This irregularity at corner is mostly localised and does not affect the flow quality at the test section (Mehta, 1978).

Figs. 8(a) and $8(\mathrm{~b})$ show the longitudinal cross-section centreline wind speed of D1 and D2 designs at wind speeds of $0.56 \mathrm{~m} \mathrm{~s}^{-1}$ and $2.22 \mathrm{~m} \mathrm{~s}^{-1}$, respectively. At position $x / L=0.5$, i.e., halfwidth of square contraction, the D1 has flow speed of $\sim 0.27 \mathrm{~m} \mathrm{~s}^{-1}$, while D2 has flow speed of $0.3 \mathrm{~m} \mathrm{~s}^{-1}$. The D1 design attains approximately half of desired wind speed of $0.56 \mathrm{~m} \mathrm{~s}^{-1}$ as compared to D2 design. This indicates that D1 design is better following the design equation, where $x / L=0.5$ is middle point for wall design change in both the designs. Similar phenomenon is also observed for wind speed of $2.2 \mathrm{~m} \mathrm{~s}^{-1}$. 


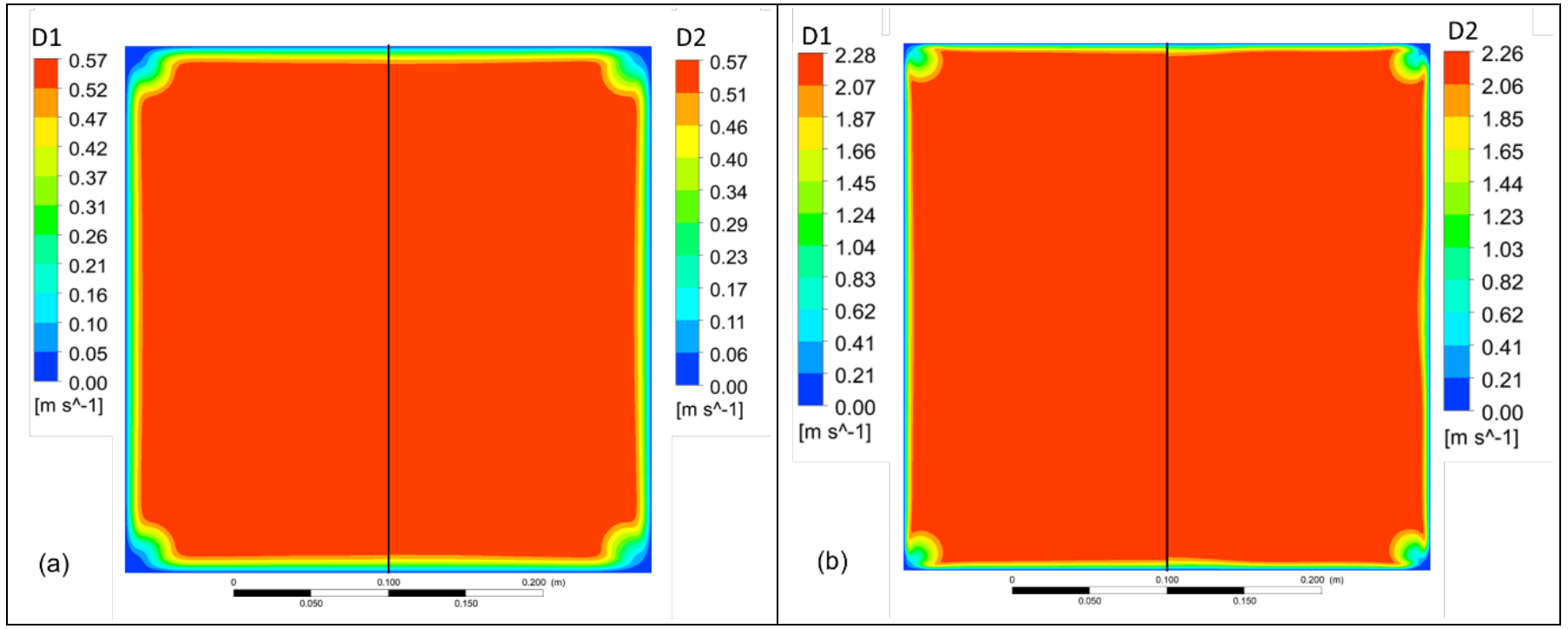

Fig. 7. The side-by-side view of velocity profiles for designs D1 and D2 at outlet position of $x=-20 \mathrm{~cm}$ for wind speeds of (a) $0.56 \mathrm{~m} \mathrm{~s}^{-1}$ and (b) $2.22 \mathrm{~m} \mathrm{~s}^{-1}$, respectively.

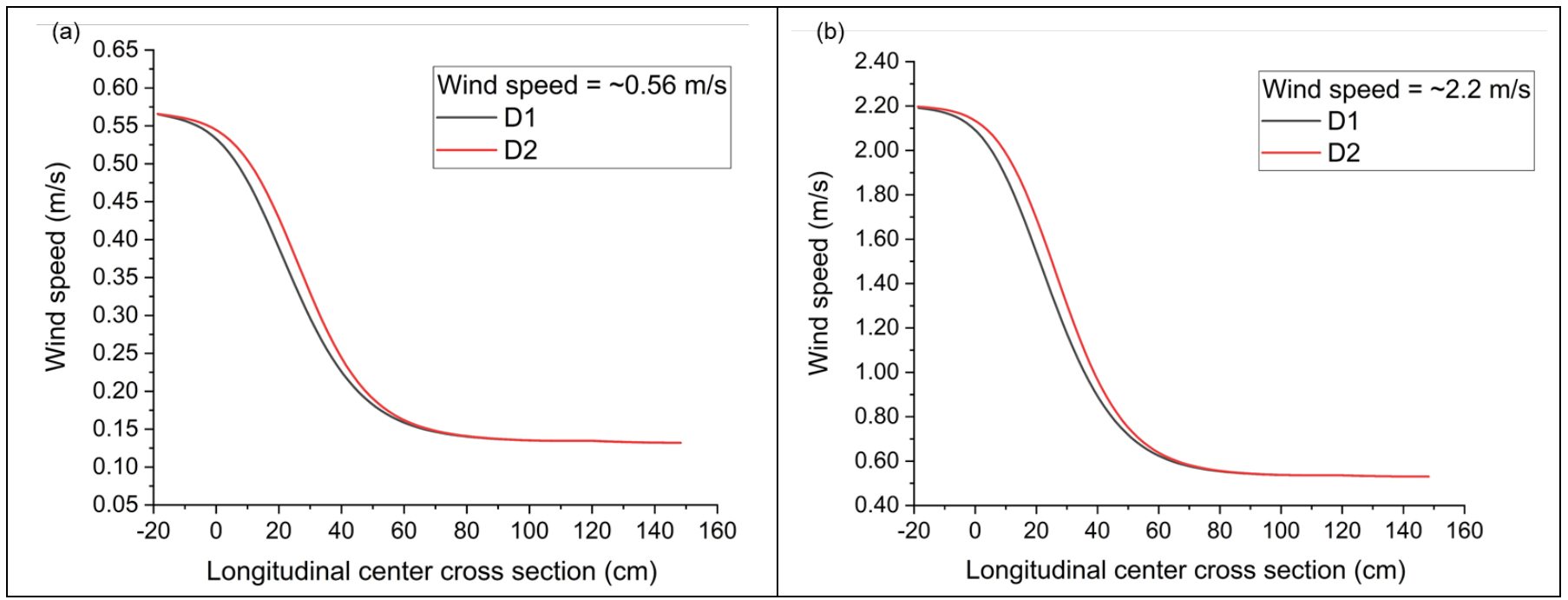

Fig. 8. Velocity profiles along longitudinal centrelines for designs D1 and D2 at wind speeds of (a) $0.56 \mathrm{~m} \mathrm{~s}^{-1}$ and (b) $2.22 \mathrm{~m} \mathrm{~s}^{-1}$, respectively.

Figs. 9(a) and 9(b) show the cross-sectional flow speed at three points, i.e., $x=34 \mathrm{~cm}(x / L=$ $0.5), x=0$ and $x=-20 \mathrm{~cm}$ positions. Both designs D1 and D2 show different approaches for attaining the flow speeds. The design D2 at any position attains higher wind speed as compared to design D1. At half-way of contraction, i.e., $x / L=0.5, \mathrm{D} 1$ and $\mathrm{D} 2$ both show different approaches to achieve the desired flow speed. The design D2 is attaining higher wind speed than D1 but at the corners, the design D2 has lower wind speed than that of D1. Similar phenomenon as described in Figs. 7(a) and 7(b) of doubling of wind speed for design D1 from position $x / L=0.5$ to $x=-20 \mathrm{~cm}$ can also be observed here for both the wind speeds. At $x=0$ position both designs show higher wind speeds at corners than at the centre. This could be result of adverse pressure gradient near the curved wall close to outlet of contraction. However, at $x=-20 \mathrm{~cm}$, the desired wind speed is maximum and uniform in majority of area for both D1 and D2 design cases. Also, D1 shows lower boundary layer thickness than that of D2 design at position $x=-20 \mathrm{~cm}$.

It also shows that the thickness of the boundary layer at the lowest speed of $0.56 \mathrm{~m} \mathrm{~s}^{-1}$ is more and gets thinner as flow increases to $2.22 \mathrm{~m} \mathrm{~s}^{-1}$ at contraction ratio of 5 to 1 for both of the designs. Similar type of flow study on contraction design which has CR of 9.88 to 1 was chosen 

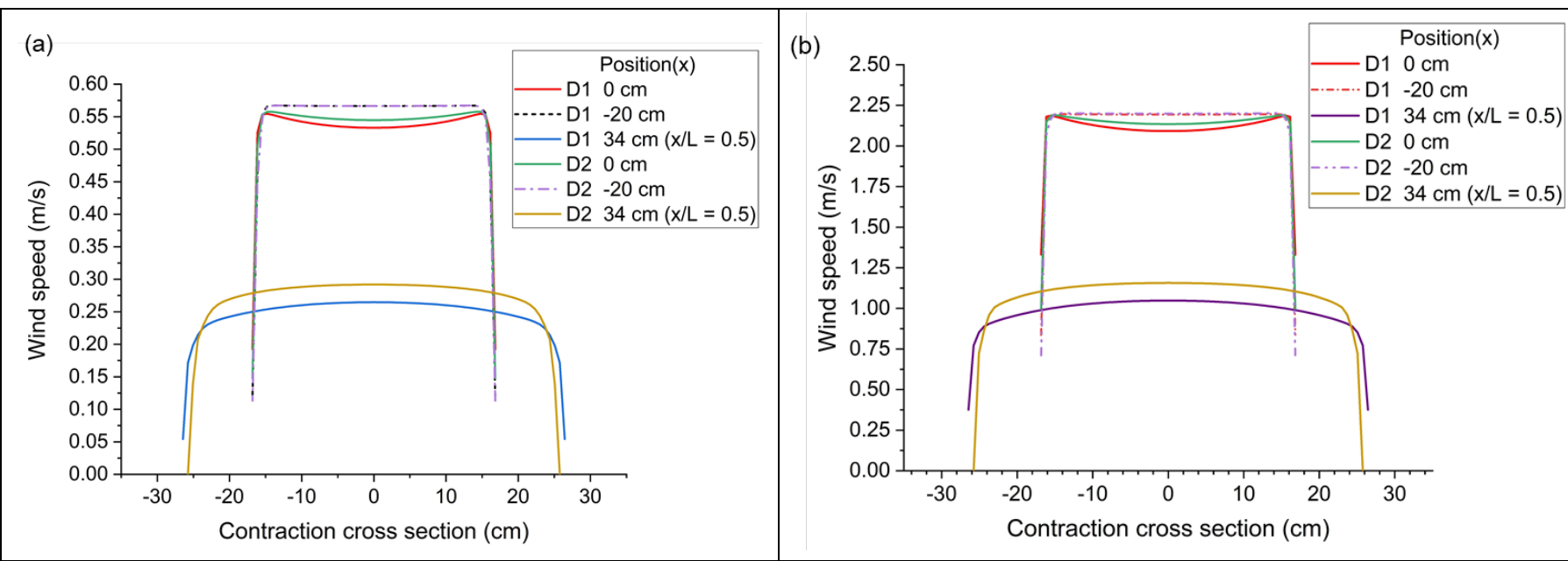

Fig. 9. Boundary layer profiles at different horizontal centre $x$ positions for design D1 and D2 at wind speeds of (a) $0.56 \mathrm{~m} \mathrm{~s}^{-1}$ and (b) $2.22 \mathrm{~m} \mathrm{~s}^{-1}$, respectively.
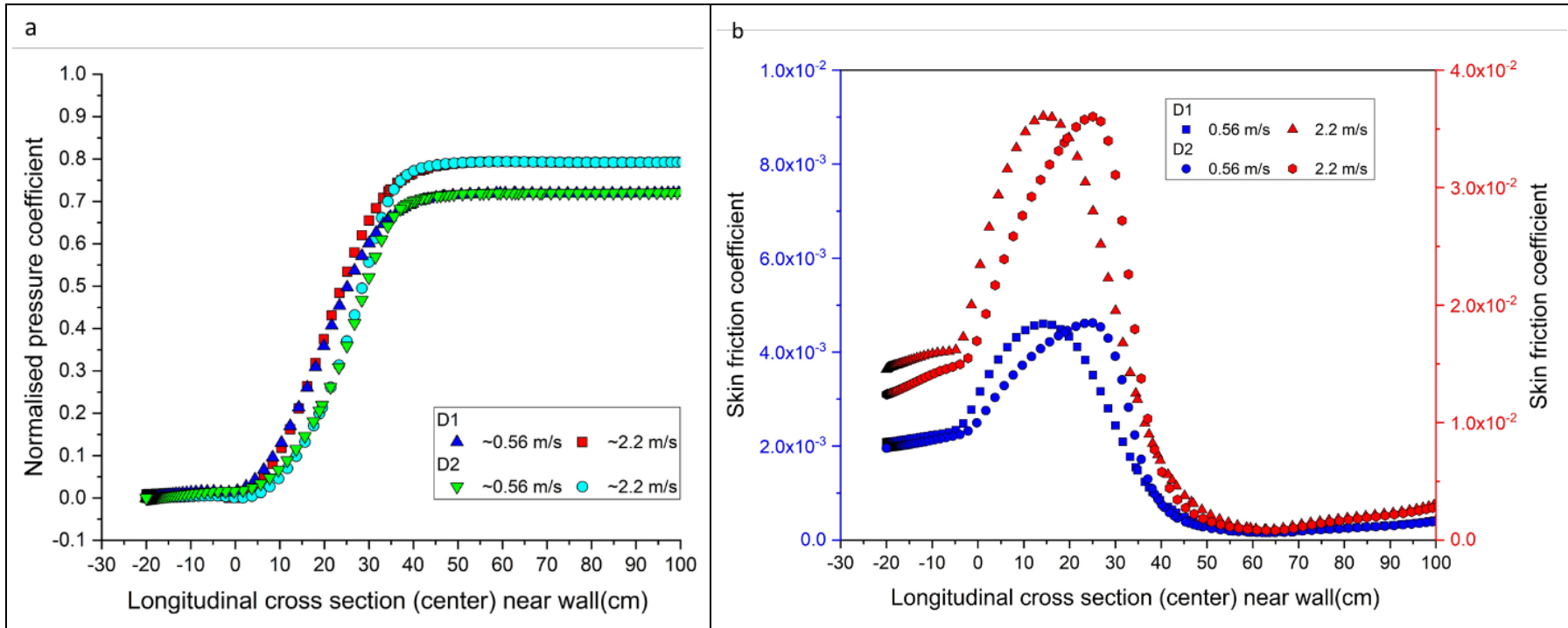

Fig. 10. (a) Pressure coefficient and (b) skin friction coefficient profiles near the wall for designs D1 and D2 at wind speeds of $0.56 \mathrm{~m} \mathrm{~s}^{-1}$ and $2.22 \mathrm{~m} \mathrm{~s}^{-1}$.

and different contraction wall shape was designed and modelled by Kao et al. (2017). In another study on a square contraction, the entrance and exit having CR of 8 to 1 was modelled, and later it was experimentally observed that at lowest testing speed, in about $85 \%$ of total cross-sectional area of the test section, the air velocity is uniform with low turbulence intensity at the centre of test section (Leifsson and Koziel, 2015).

Two other parameters that are indicator of boundary layer separation are pressure coefficient and skin friction coefficient near the wall of contraction. Figs. 10(a) and 10(b) show pressure coefficient at the centre near the wall (first grid level) of contraction (longitudinal) at wind speeds of $0.56 \mathrm{~m} \mathrm{~s}^{-1}$ and $2.22 \mathrm{~m} \mathrm{~s}^{-1}$, respectively. In both the cases at first, pressure coefficient was constant up to $x=34 \mathrm{~cm}$ position i.e., $x / L=0.5$. Down to $x / L=0.5$, a monotonic decrease in the pressure coefficient with steeper slope was observed, and it was reducing smoothly. Figures also show that D2 is reducing the pressure much faster than D1. At outlet, both show slight adverse pressure gradient but later reached to zero (position: $-5 \mathrm{~cm} \geq 0 \geq 5 \mathrm{~cm}$ ). Skin friction coefficient as shown in Figs. 10(c) and 10(d) for design D1 and D2 at both wind speeds does not reach to zero which indicates no flow separation. On observing carefully at near position $x=-20 \mathrm{~cm}, \mathrm{D} 1$ show higher skin friction coefficient value than that of D2 design. 
Based on above contraction design evaluation of D1 and D2, D1 design was chosen for development of contraction, because of better flow stability in both wind speeds at outlet, smoother increment in flow velocity, lower boundary layer thickness, higher pressure coefficient and skin friction coefficient than that of D2 design.

\subsection{Flow Uniformity inside Test Section}

Along the cross-section of test section, at 25 locations wind speed was measured (Fig. 3). At a wind speed of 2 and $8 \mathrm{~km} \mathrm{~h}^{-1}$, the uniformity inside the test section is consistent at the centre of the test section. The plots of velocities measured at different locations inside the test section are shown in Figs. 11(a) and 11(b). It indicates that the mean velocity at $2 \mathrm{~km} \mathrm{~h}^{-1}$ and $8 \mathrm{~km} \mathrm{~h}^{-1}$ is uniform across $90-95 \%$ of cross-sectional area. The contour plots given as Figs. 11 (c) and 11(d), show that the coefficient of variation (CV) for wind speed of $2 \mathrm{~km} \mathrm{~h}^{-1}$ is maximum of $4 \%$, whereas for $8 \mathrm{~km} \mathrm{~h}^{-1}$, it is decreased to maximum of $1.5 \%$, respectively at the centre of test section. As per U.S. EPA guidelines, the mean deviation of wind speed inside the test section is permitted to lie within the range of $10 \%$.

The turbulence intensity (TI) contours inside the test section for wind speeds of 2 and $8 \mathrm{~km} \mathrm{~h}^{-1}$ are shown in Figs. 11(e) and 11(f), respectively. It shows the fluctuation of wind speed is maximum at $2 \mathrm{~km} \mathrm{~h}^{-1}$, i.e., $4 \%$ while at $8 \mathrm{~km} \mathrm{~h}^{-1}$, it decreased to $1.2 \%$. At the centre of test section, the $\mathrm{TI}$ is low in both wind speeds while at wall, the $\mathrm{TI}$ increases but lies far below the range of $10 \%$. These results agree with the study conducted by Leifsson and Koziel (2015) as described in Section 3.1. Moreover, it is well known that the Tl decreases with increase in wind speed. In another comparison with a previous study conducted by Hinds and Kuo (1995) where TI was reported to be as maximum as $14 \%$ at wind speed of $0.2 \mathrm{~m} \mathrm{~s}^{-1}$, the developed wind tunnel at its lowest wind speed is agreed well.

\subsection{Aerosol Uniformity Test}

For determining the effectiveness of PM samplers, most of the researchers have used monodisperse aerosol. As shown in Table 1, several researchers (Weiner et al., 1988; Ranade et al., 1990; Cheng et al., 2004; Lee et al., 2013) have used Vibrating Orifice Aerosol Generator (VOAG) for generation of monodisperse test particles. U.S. EPA guidelines also recommend the use of VOAG for monodisperse test particle generation for accurate confirmation of sampler effectiveness and $D_{50}$ cutoff. However, Dart et al. (2018) stated that monodisperse test particle generation and testing is time-consuming and labour-intensive, and even if valid test results are obtained during wind tunnel operation, a comprehensive evaluation of a sampler inlet can require many weeks or months to complete the exercise. Moreover, aerosol concentrations generated by VOAG are low; thus, test parameters such as particle loading effect on sampler effectiveness cannot be determined. On the other hand, ambient aerosols are polydisperse in nature. Polydispersity of test aerosol enables us to check the performance of PM instrument system under similar-toambient condition as real case. Therefore, to evaluate the uniformity of particle distribution in wind tunnel test section, we used polydisperse test dust particle, i.e., ambient dust collected as discussed above.

With the aim to get low turbulence (and for this a static aerosol distribution system inside the tunnel is preferred), at first instance we installed the single Venturi pump at the centre of settling chamber. The Venturi pump is good enough for breaking down the loosely bound dust particles and their uniform mixing (Krug et al., 2017). The arrangement of conical nozzles is based on troubleshoots in the experiments.

Dust concentration was measured using gravimetric method at 5 test points (Fig. 5). Fig. 12(a) shows that the mean deviation in mass concentration measured at $0.56 \mathrm{~m} \mathrm{~s}^{-1}\left(2 \mathrm{~km} \mathrm{~h}^{-1}\right)$ in all surrounding 4 isokinetic samplers (relative to the centre test point) is in the range of $-6.7 \%$ to $5 \%$, while at $2.22 \mathrm{~m} \mathrm{~s}^{-1}\left(8 \mathrm{~km} \mathrm{~h}^{-1}\right)$ this is calculated to be in the range of $-8 \%$ to $-0.3 \%$. This shows that the dust concentration is reasonably homogeneous throughout the test section and is within the $10 \%$ limit range (U.S. EPA guidelines).

The gravimetric method can give only an average mass concentration of dust. The deviation in mass concentration may or may not be measurable even when the particle number concentration is changed reasonably. Therefore, we also measured the particle size distribution of dust using APS 


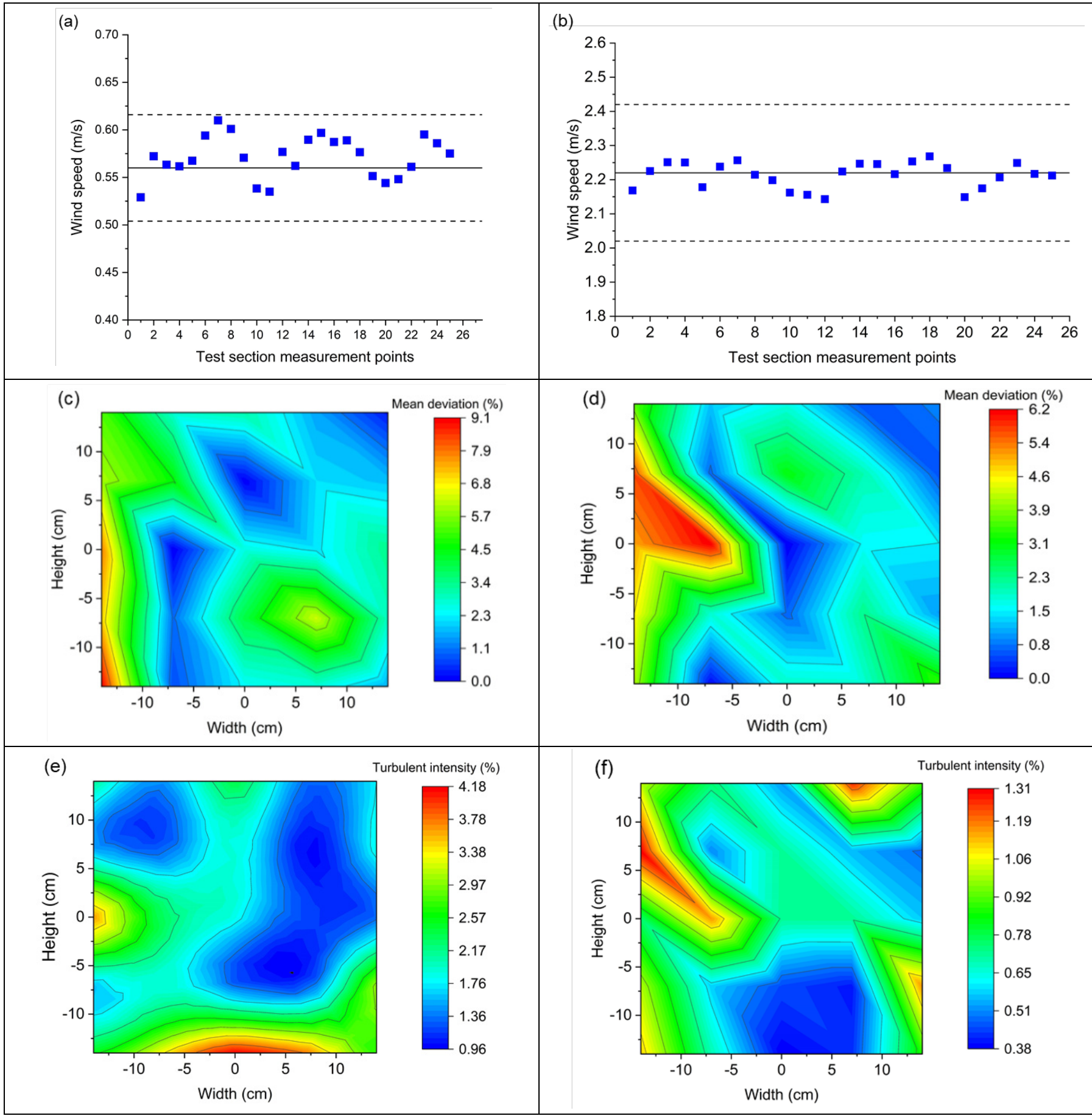

Fig. 11. Wind speed profile in different test grids at (a) $0.56 \mathrm{~m} \mathrm{~s}^{-1}$ and (b) $2.22 \mathrm{~m} \mathrm{~s}^{-1}$; mean deviation (coefficient of variation) at set wind speeds of (c) $0.56 \mathrm{~m} \mathrm{~s}^{-1}$ and (d) $2.22 \mathrm{~m} \mathrm{~s}^{-1}$; turbulent intensity at set wind speeds of (e) $0.56 \mathrm{~m} \mathrm{~s}^{-1}$ and (f) $2.22 \mathrm{~m} \mathrm{~s}^{-1}$.

at all isokinetic sampling locations at wind speeds of $0.56 \mathrm{~m} \mathrm{~s}^{-1}$ and $2.22 \mathrm{~m} \mathrm{~s}^{-1}$. The ratio of particle size distribution between centre isokinetic sampler and isokinetic sampler at sides is used to calculate the coefficient of variation, and the results are shown in Fig. 12(b). The CV is $7.3 \%$ and $4 \%$ at $0.56 \mathrm{~m} \mathrm{~s}^{-1}$ and $2.22 \mathrm{~m} \mathrm{~s}^{-1}$, respectively and it is well below $10 \%$ on an average. This shows the acceptable homogeneity of test dust and also the spatial uniformity of number concentration distribution inside the test section. The only requirement as mentioned in U.S. EPA guidelines to determine sampler effectiveness or $D_{50}$ cutoff of PM sampler is the aerosol uniformity. Inside the test section, it should not deviate more than $10 \%$ from the co-located isokinetic samplers. Thus, the developed aerosol wind tunnel meets this requirement. 


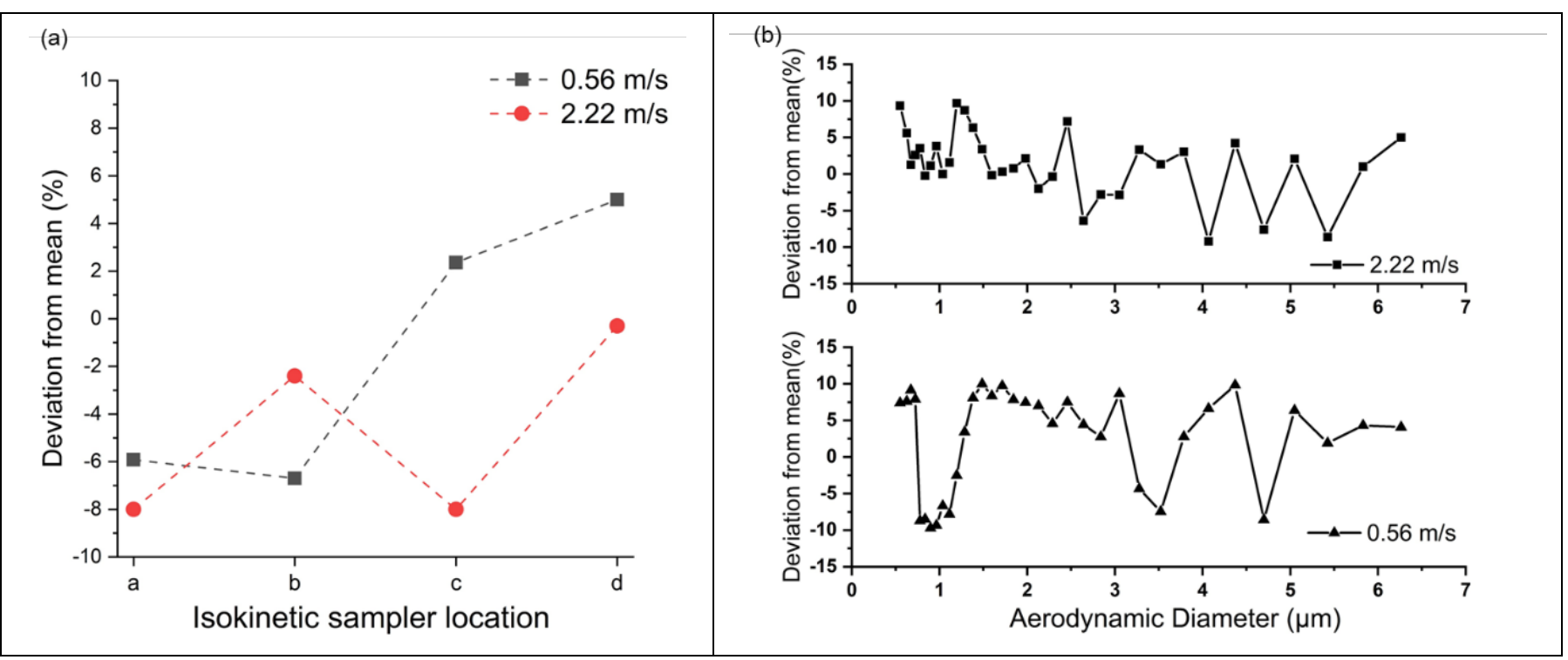

Fig. 12. Percentage deviation from mean (absolute deviation) of dust concentration measured using (a) gravimetric method and (b) a reference instrument (APS).

\subsection{Compact Wind Tunnel Application}

\subsubsection{Penetration efficiency testing}

Calibration of $\mathrm{PM}_{2.5}$ impactor using wind tunnel as specified in U.S. EPA requires the use of monodisperse aerosol as testing material and fluorometre to quantify the penetration efficiency (40 CFR 53.62). As stated above, this method is time-consuming and tedious to perform (Dart et al., 2018). Therefore, we followed the method suggested by Maynard and Kenny (1995) and Kenny and Liden (1991) for the determination of penetration efficiency of PM$_{2.5}$ WINS impactor using developed wind tunnel. We used polydisperse aerosol (dust particle properties) as testing material and a real-time particle sizer to measure particle size and number concentration as discussed above. In present study, the measured $\mathrm{D}_{50}$ cutoff diameter of $\mathrm{PM}_{2.5}$ WINS impactor and VSCC cyclone is determined to be $2.44 \pm 0.05 \mu \mathrm{m}$ (where $\pm 0.05 \mu \mathrm{m}$ is the expanded uncertainty of measurement which is about $2 \%$ ) and $2.54 \pm 0.05 \mu \mathrm{m}$ respectively. The results agree to the several other experimental $D_{50}$ cutoff testing results conducted by Peters et al. (2001) and Vanderpool et al. (2001) using U.S. EPA-specified method (Fig. 13).

\subsubsection{Low-cost sensor testing results}

Developed wind tunnel was also used for performance evaluation of low-cost PM sensor using smoke particles following the method as discussed above. Firstly, two PM sensors are intercompared for $\mathrm{PM}_{2.5}$ mass concentration measurement in wind tunnel, and results are plotted as shown in Fig. 14(a). The results on 1:1 scale shows excellent linearity in between these PM sensors $\left(R^{2}=\right.$ 0.99 and slope $=$ close to 1$)$. This also indicates the uniformity of test aerosols inside the test section of developed wind tunnel. Secondly the sensor is also evaluated using a calibrated APS (refer as "reference instrument"). The reference instrument (the particle sizer) gives accurate sizing and individual particle size bin number concentration. Therefore, we compared $\mathrm{PM}_{2.5}$ mass concentration measured by the sensor to corresponding $\mathrm{PM}_{2.5}$ cumulative particle number concentration measured by reference APS. Fig. 14(b) inset shows an excellent correlation between PM sensor and APS data. The correlation coefficient $\left(R^{2}\right)$ achieved for this $P M_{2.5}$ mass concentration, i.e., up to $150 \mu \mathrm{g} \mathrm{m}^{-3}$ is 0.99 , while at wider concentration, i.e., of $5-900 \mu \mathrm{g} \mathrm{m}^{-3}$ both the measurements are moderately correlated, but the second-order polynomial fit is again highly correlated with $\mathrm{R}^{2}$ value of 0.99 , Fig. $14(\mathrm{~b})$. These results agree to similar research conducted by Kelly et al. (2016) using alumina oxide as test particles and Levy Zamora et al. (2019) which were used smoke particles (generated using incense sticks), and both concluded that the differences observed between low-cost sensor and research-grade instrument like APS data are mostly because of particle properties and ambient measuring conditions. 


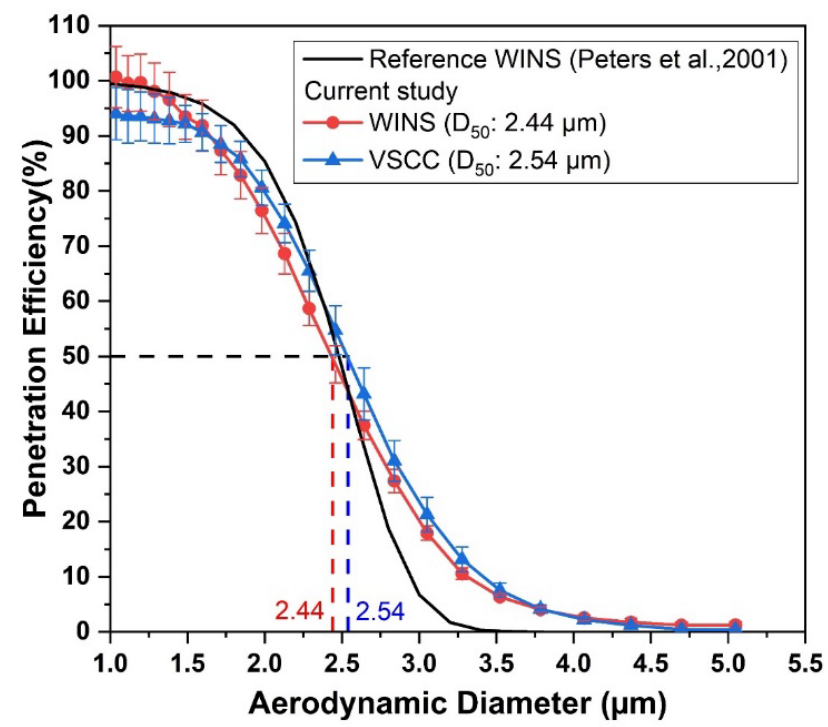

Fig. 13. Penetration efficiency curves of $\mathrm{PM}_{2.5}$ WINS impactor and VSCC cyclone at wind speed of $2.22 \mathrm{~m} \mathrm{~s}^{-1}\left(8 \mathrm{~km} \mathrm{~h}^{-1}\right)$.
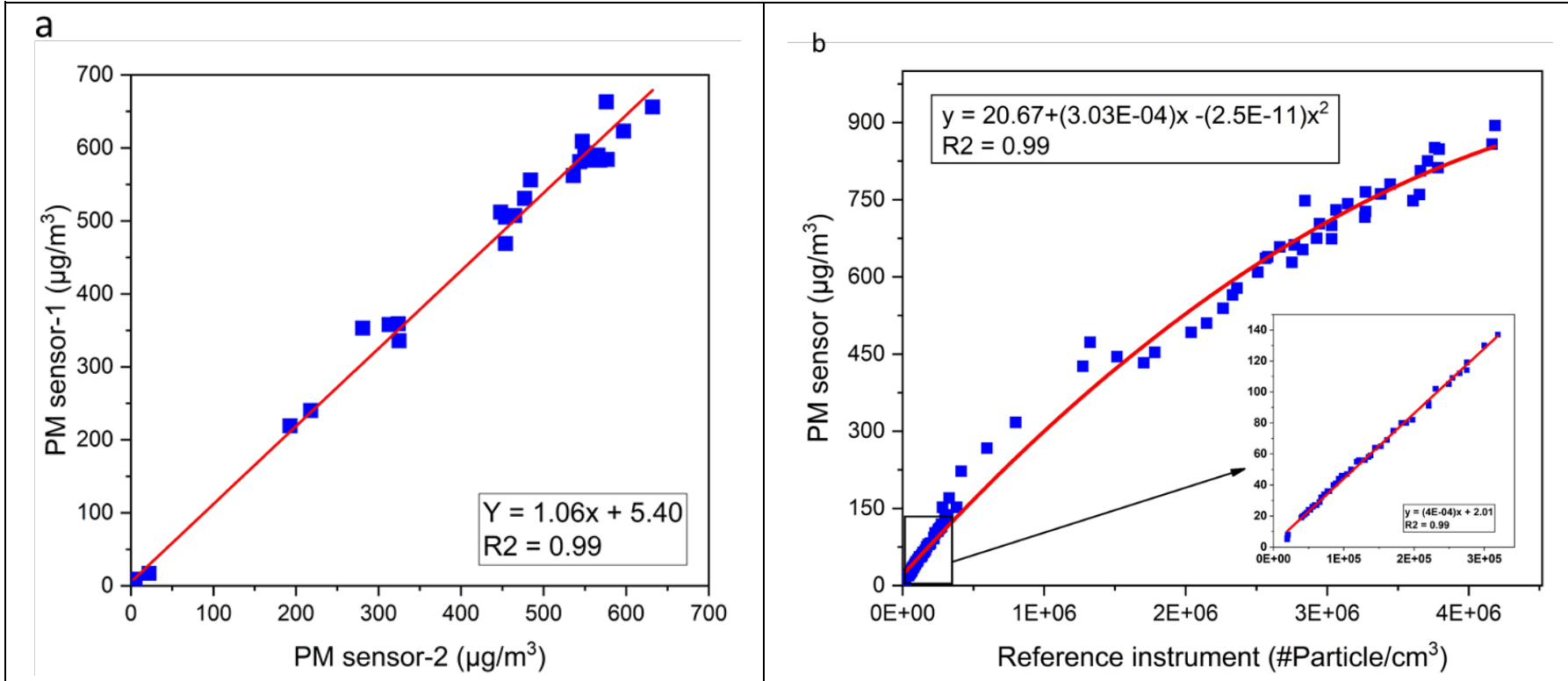

Fig. 14. Low-cost PM sensor performance results: (a) comparison between sensors and (b) at wider concentration (5-900 $\mu \mathrm{g} \mathrm{m}^{-3}$ ) with inset figure of comparison between sensor and reference instrument (APS) at low concentration (up to $150 \mu \mathrm{g} \mathrm{m} \mathrm{m}^{-3}$ ).

\section{CONCLUSIONS}

We developed a compact low-speed wind tunnel (total length $=4.2 \mathrm{~m}$, test section $=0.34 \mathrm{~m} \times$ $0.34 \mathrm{~m}$ ) that can be used to conduct performance checks of aerosol-measuring/sampling instruments. To minimize boundary layer separation, we based the geometry of the critical contraction section on theoretical design principles and numerical simulations. We also customized the generation and delivery system for the test aerosol and demonstrated the application of the wind tunnel for different cases.

We conducted CFD simulations of the theoretical contraction design, which incorporated a porous model to mimic the flow straightening of a honeycomb, at wind velocities of 2 and $8 \mathrm{~km} \mathrm{~h}^{-1}$. The virtual contraction exhibited minimal boundary layer separation and a smooth flow at the outlet 
of the contraction. An assessment of the flow quality at multiple sampling points inside the test section showed maximum mean deviations of $4 \%$ and $1.5 \%$ and turbulence intensities of $4 \%$ and $1.2 \%$ at 2 and $8 \mathrm{~km} \mathrm{~h}^{-1}$, respectively, which fall well within the $10 \%$ limit specified by U.S. EPA.

Additionally, we measured the particle stability and uniformity of polydisperse aerosol at air velocities of 2 and $8 \mathrm{~km} \mathrm{~h}^{-1}$ in the test section with multiple isokinetic samplers. The particle mass ranged from $-6.7 \%$ to $5 \%$ and from $-8 \%$ to $-0.3 \%$ at 2 and $8 \mathrm{~km} \mathrm{~h}^{-1}$, respectively, whereas the number-size distribution varied by $10 \%$. Importantly, when using polydisperse aerosol as test particles, particle counts for a given size must be stable in order to determine the efficiency of a sampler.

Following U.S. EPA-specified requirements for $\mathrm{PM}_{2.5}$ measurement, we evaluated the penetration efficiencies of the WINS and VSCC at a wind speed of $8 \mathrm{~km} \mathrm{~h}^{-1}$ and obtained $50 \%$ cutoff diameters of $2.44 \pm 0.05 \mu \mathrm{m}$ and $2.54 \pm 0.05 \mu \mathrm{m}$, respectively, fulfilling the calibration and performance criteria. Furthermore, we investigated the performance of a low-cost PM sensor, the Plantower PMS3003, at particle concentrations of $5-900 \mu \mathrm{g} \mathrm{m}^{-3}$ at a wind speed of $2 \mathrm{~km} \mathrm{~h}^{-1}$ in the test section by comparing the measurements between different units and between a PMS3003 and a reference instrument. Although the former displayed a strong and perfectly linear correlation $\left(R^{2}=0.99\right)$, the latter showed a linear correlation $\left(R^{2}=0.99\right)$ at low concentrations but a polynomial fit at higher concentrations as well as for wider ranges of concentration.

Our findings suggest that the developed wind tunnel is suitable for various applications in aerosol research, including sampler testing, aspiration and deposition estimation, and low-cost PM sensor assessment. Finally, maintaining the homogeneity and stability of the test aerosol at higher air velocities for longer durations is easier for this wind tunnel, owing to its compactness, than for larger ones.

\section{ACKNOWLEDGEMENTS}

This development is a part of internal project funding, OLP 183832. Director, CSIR-NPL, is acknowledged for providing all facilities and support for this development. PP thanks to DST, New Delhi, for providing JRF/SRF fellowship under a project (IDP/IND/17/2013). All members of Gas Metrology Group and past and present divisional heads of the ESBMD at CSIR-NPL are also acknowledged for all their support and help.

\section{REFERENCES}

Ansys, Fluent (2017). R2 User's Guide. ANSYS Inc.

Aggarwal, S.G., Kumar, S., Mandal, P., Sarangi, B., Singh, K., Pokhariyal, J., Mishra, S.K., Agarwal, S., Sinha, D., Singh, S., Sharma, C., Gupta, P.K. (2013). Traceability issue in $\mathrm{PM}_{2.5}$ and $\mathrm{PM}_{10}$ measurements. MAPAN 28, 153-166. https://doi.org/10.1007/s12647-013-0073-x

Bell, J.H., Mehta, R.D. (1988). Contraction Design for small low-speed wind tunnels; NASA Ames Research Center, Moffett Field, CA, USA.

Cattafesta, L., Bahr, C., Mathew, J. (2010). Fundamentals of wind-tunnel design. Encyclopedia of Aerospace Engineering. https://doi.org/10.1002/9780470686652.eae532

Chen, J., Shaw, B.W., Ortiz, C.A., Faulkner, W.B., Parnell, C. (2006). A dust wind tunnel for particulate matter sampling studies. In 2006 ASAE Annual Meeting (p. 1). American Society of Agricultural and Biological Engineers, St. Joseph, Michigan. https://doi.org/10.13031/2013.21 154

Cheng, Y.S., Irshad, H., McFarland, A.R., Su, W.C., Zhou, Y., Barringer, D. (2004). An aerosol wind tunnel for evaluation of massive-flow air samplers and calibration of Snow-White sampler. Aerosol Sci. Technol. 38, 1099-1107. https://doi.org/10.1080/02786820490494034

Chung, I.P., Dunn-Rankin, D., Phalen, R.F., Oldham, M.J. (1992). Low-cost wind tunnel for aerosol inhalation studies. Am. Ind. Hyg. Ass. J. 53, 232-236. https://doi.org/10.1080/1529866929135 9573

Coffey, E.R., Pfotenhauer, D., Mukherjee, A., Agao, D., Moro, A., Dalaba, M., Begay, T., Banacos, N., Oduro, A., Dickinson, K.L., Hannigan, M.P. (2019). Kitchen area air quality measurements in northern Ghana: Evaluating the performance of a low-cost particulate sensor within a 
household energy study. Atmosphere 10, 400. https://doi.org/10.3390/atmos10070400

Dart, A., Krug, J.D., Witherspoon, C.L., Gilberry, J., Malloy, Q., Kaushik, S., Vanderpool, R.W. (2018). Development of polydisperse aerosol generation and measurement procedures for wind tunnel evaluation of size-selective aerosol samplers. Aerosol Sci. Technol. 52, 957-970. https://doi.org/10.1080/02786826.2018.1469728

U.S. EPA (1998). 40 CFR part 50, National Ambient Air Quality Standards for Particulate Matter. United States Environmental Protection Agency.

U.S. EPA (2006). 40 CFR Parts 53, General requirements for an equivalent method determination. United States Environmental Protection Agency.

Fang, F.M., Chen, J.C., Hong, Y.T. (2001). Experimental and analytical evaluation of flow in a square-to-square wind tunnel contraction. J. Wind Eng. Ind. Aerodyn. 89, 247-262. https://doi.org/10.1016/S0167-6105(00)00080-5

Greenstone, M., Hanna, R. (2014). Environmental regulations, air and water pollution, and infant mortality in India. Am. Eco. Rev. 104, 3038-72. https://doi.org/10.1257/aer.104.10.3038

Hinds, W.C., Kuo, T.L. (1995). A low velocity wind tunnel to evaluate inhalability and sampler performance for large dust particles. App. Occup. Environ. Hyg. 10, 549-556. https://doi.org/ 10.1080/1047322X.1995.10389073

Jaques, P.A., Hsiao, T.C., Gao, P. (2011). A recirculation aerosol wind tunnel for evaluating aerosol samplers and measuring particle penetration through protective clothing materials. App. Occup. Environ. Hyg. 55, 784-796. https://doi.org/10.1093/annhyg/mer062

Kao, Y.H., Jiang, Z.W., Fang, S.C. (2017). A computational simulation study of fluid mechanics of low-speed wind tunnel contractions. Fluids 2, 23. https://doi.org/10.3390/fluids 2020023

Kelleher, S., Quinn, C., Miller-Lionberg, D., Volckens, J. (2018). A low-cost particulate matter (PM 2.5$)$ monitor for wildland fire smoke. Atmos. Meas. Tech. 11, 1087-1097. https://doi.org/1 0.5194/amt-11-1087-2018

Kelly, K.E., Whitaker, J., Petty, A., Widmer, C., Dybwad, A., Sleeth, D., Butterfield, A. (2017). Ambient and laboratory evaluation of a low-cost particulate matter sensor. Environ. Pollut. 221, 491-500. https://doi.org/10.1016/j.envpol.2016.12.039

Kenny, L.C., Liden, G. (1991). A technique for assessing size-selective dust samplers using the APS and polydisperse test aerosols. J. Aerosol Sci. 22, 91-100. https://doi.org/10.1016/00218502(91)90095-Y

Krug, J.D., Dart, A., Witherspoon, C.L., Gilberry, J., Malloy, Q., Kaushik, S., Vanderpool, R.W. (2017). Revisiting the size selective performance of EPA's high-volume total suspended particulate matter (Hi-Vol TSP) sampler. Aerosol Sci. Technol. 51, 868-878. https://doi.org/10. 1080/02786826.2017.1316358

Kumar, A., Ambade, B., Sankar, T.K., Sethi, S.S., Kurwadkar, S. (2020). Source identification and health risk assessment of atmospheric $\mathrm{PM}_{2.5}$-bound polycyclic aromatic hydrocarbons in Jamshedpur, India. Sustainable Cities Soc. 52, 101801. https://doi.org/10.1016/j.scs.2019.101801

Lee, S., Yu, M., Kim, H.H. (2013). Development of aerosol wind tunnel and its application for evaluating the performance of ambient $\mathrm{PM}_{10}$ inlets. Atmos. Pollut. Res. 4, 323-328. https://doi.org/10.5094/APR.2013.036

Leifsson, L., Koziel, S. (2015). Simulation-driven design of low-speed wind tunnel contraction. J. Comput. Sci. 7, 1-12. https://doi.org/10.1016/j.jocs.2014.12.004

Levy Zamora, M., Xiong, F., Gentner, D., Kerkez, B., Kohrman-Glaser, J., Koehler, K. (2018). Field and laboratory evaluations of the low-cost plantower particulate matter sensor. Environ. Sci. Technol. 53, 838-849. https://doi.org/10.1021/acs.est.8b05174

Li, J., Mattewal, S.K., Patel, S., Biswas, P. (2020). Evaluation of nine low-cost-sensor-based particulate matter monitors. Aerosol Air Qual. Res. 20, 254-270. https://doi.org/10.4209/aaq r.2018.12.0485

Mansoor, S. (2019). 'Air Pollution Turned India's Capital Into a 'Climate Emergency.' It's Part of a Global Trend Killing 7 Million Prematurely Each Year (online)', TIME, 05 November. https://time.com/5718012/new-delhi-pollution-2019/ (accessed 21 January 2020).

Maynard, A.D., Kenny, L.C. (1995). Performance assessment of three personal cyclone models, using an aerodynamic particle sizer. J. Aerosol Sci. 26, 671-684. https://doi.org/10.1016/00218502(94)00131-H

Mehta, R.D. (1978). Aspects of the Design and Performance of Blower Wind Tunnel Component. 
Ph.D. Thesis, Department of Aeronautics, Imperial College, University of London, London, UK.

Mehta, R.D., Bradshaw, P. (1979). Design rules for small low speed wind tunnels. Aeronaut. J. 83, 43-453.

Morel, T. (1975). Comprehensive design of axisymmetric wind tunnel contractions. J. Fluids Eng 97, 225-233. https://doi.org/10.1115/1.3447255

National Ambient Air Quality Standards (NAAQS) (2009). Central Pollution Control Board Notification (http://www.cpcb.nic.in/upload/Latest/Latest_48_FINAL_AIR_STANDARD.pdf) in the Gazette of India, Extraordinary, New Delhi, 18th November, 2009.

Okuda, T., Isobe, R., Nagai, Y., Okahisa, S., Funato, K., Inoue, K. (2015). Development of a highvolume $\mathrm{PM}_{2.5}$ particle sampler using impactor and cyclone techniques. Aerosol Air Qual. Res. 15, 759-767. https://doi.org/10.4209/aaqr.2014.09.0194

Peters, T.M., Vanderpool, R.W., Wiener, R.W. (2001). Design and calibration of the EPA PM2.5 well impactor ninety-six (WINS). Aerosol Sci. Technol. 34, 389-397. https://doi.org/10.1080/02786 820120352

Purohit, P., Amann, M., Kiesewetter, G., Chaturvedi, V., Rafaj, P., Dholakia, H.H., Nagar Koti, P., Klimont, Z., Borken-Kleefeld, J., Gómez-Sanabria, A., Schöpp, W. (2019). Pathways to Achieve National Ambient Air Quality Standards (NAAQS) in India.

Ranade, M.B., Woods, M.C., Chen, F.L., Purdue, L.J., Rehme, K.A. (1990). Wind tunnel evaluation of PM10 samplers. Aerosol Sci. Technol. 13, 54-71. https://doi.org/10.1080/02786829008959424

Reist, P.C., Taylor, L. (2000). Development and operation of an improved turntable dust feeder. Powder Technol. 107, 36-42. https://doi.org/10.1016/S0032-5910(99)00082-0

TSI Incorporated (2012). Model 3321 Aerodynamic Particle Sizer spectrometer: Operation and Service Manual. http://webx.ubi.pt/ goa/Manuals/APS3321/3321_APS_1930092G.pdf

Vanderpool, R.W., Peters, T. M., Natarajan, S., Tolocka, M.P., Gemmill, D.B., Wiener, R.W. (2001) Sensitivity analysis of the USEPA WINS PM2.5 separator Aerosol Sci. Technol. 34, 465-476. https://doi.org/10.1080/02786820120868

Wagner, J., Leith, D. (2001). Passive aerosol sampler. Part II: Wind tunnel experiments. Aerosol Sci. Technol. 34, 193-201. https://doi.org/10.1080/027868201300034826

Wiener, R.W., Okazaki, K., Willeke, K. (1988). Influence of turbulence on aerosol sampling efficiency. Atmos. Environ. 22, 917-928. https://doi.org/10.1016/0004-6981(88)90269-7

Zanoun, E.S. (2018). Flow characteristics in low-speed wind tunnel contractions: Simulation and testing. Alexandria Eng. J. 57, 2265-2277. https://doi.org/10.1016/j.aej.2017.08.024 